\title{
Isolation and Classification of a New Series of Azotobacter Bacteriophages
}

\author{
BY J. T. DUFF* aND O. WYSS \\ Department of Bacteriology, University of Texas, Austin, Texas
}

(Received 26 August 1960)

\section{SUMMARY}

Successful isolation of azotobacter phages from soil samples was accomplished by using a modified Burk's nitrogen-free medium with sucrose as the carbon source. The natural azotobacter flora in the soil samples served as the enrichment strains and the medium was not further enriched by the addition of laboratory cultures of the bacteria. Phage titres as high as $5.5 \times 10^{\circ}$ plaque-forming units $/ \mathrm{ml}$. were obtained when the indicator strain for phage assays was Azotobacter vinelandii 0 . On the basis of plaque morphology, nine phage isolates were obtained and purified by standard techniques. The plaques formed by the phages consisted of a central clear area surrounded by a halo and ranged from 1 to $7 \mathrm{~mm}$. in diameter. Antiphage sera were produced in rabbits against a previously isolated phage and the new isolates; on the basis of cross-neutralization experiments with homologous and heterologous antisera, the 10 phages were placed into four major serological groups. Groups I and II contained four phages each, and groups III and IV contained one phage each. The degree of serological relatedness among the phages within groups I and II was investigated. A survey of 48 azotobacter strains showed that 11 out of $12 \mathrm{~A}$. vinelandii strains and 14 out of $25 \mathrm{~A}$. chroococcum strains showed plaque formation by one or more of the phages. Strains of $A$. agilis, $A$. macrocytogenes, $A$. insigne and $A$. indicus were not lysed by the phages. The value of the present series of phages in the classification of the genus Azotobacter was discussed.

\section{INTRODUCTION}

A bacteriophage for certain strains of the genus Azotobacter designated A. vinelandii was originally isolated and characterized by Monsour (1954), Monsour, Wyss \& Kellogg (1955) and Kellogg (1957). Since plaques were not observed with the non-pigmented strains of $\boldsymbol{A}$. agilis or strains of $\boldsymbol{A}$. chroococcum (Monsour et al. 1955), the securing of additional phages appeared desirable since they would serve as a supplementary tool in the study of ecology and mutations in these organisms and would be an aid in the species designation of this genus. In addition, most of our present information regarding the bacteriophages has resulted from investigations mainly on the coli phages. Further characterization of additional bacteriophages and phage host systems would aid in confirming and generalizing phenomena already postulated, or might lead to new developments. The azotobacters are especially suited to such an investigation because of their many unique characteristics. They

\footnotetext{
* Present address: Fort Detrick, Frederick, Maryland, U.S.A.
} 
are larger than the average bacteria, are capable of abundant growth in a simple medium free from combined nitrogen, possess a high respiratory activity and to a certain extent are genetically stable organisms. The present investigation describes the isolation and classification of a new series of azotobacter phages.

\section{METHODS}

Strains. Most of the work was accomplished by using Azotobacter vinelandii $\mathbf{0}$, a strain originally obtained from the University of Wisconsin. This strain was subcultured every 4 days on Burk's modified nitrogen-free medium and the colonial morphology of the strain was routinely examined by visual inspection of individual clones, with the use of oblique illumination. On several occasions a smooth clone with the least amount of opaqueness was selected and purified by dilution and plating. Incubation was at $88^{\circ}$ for $24-48 \mathrm{hr}$. Other strains of azotobacter used included the following: $A$. vinelandii, American Type Culture Collection (hereafter referred to as ATCC) strains 478, 7484, 7487, 7489, 7492, 7496, 9046, 9047, 9104, 12887; University of Texas Stock Culture Collection (hereafter referred to as UT) strain K; $A$. agilis, ATCC strains 7494, 9040, 9042, 9570, 12838; UT strain M; $A$. chroococcum, ATCC strains 480, 4412, 7486, 7488, 7490, 7491, 7493, 7497, 7498, 7499, 9048, 9044, 9045, 9048, 9049, 9051, 9885, 9544, 12981; UT strains A, B, C, D, E, F, J, S; A. indicus, ATCC strains 9037, 9088, 9089, 9540; A. macrocytogenes, ATCC strains 12834, 12835, 12336; $A$. insigne strains 8 and 2, received from Dr Vagn Jensen (University of Lund, Lund, Sweden).

Media. The following media were used:

Burk's modified nitrogen-free medium (Kellogg, 1957). The medium contained (g./1.): $\mathrm{Na}_{2} \mathrm{HPO}_{4}, 0.189 ; \mathrm{KH}_{2} \mathrm{PO}_{4}, 0.011 ; \mathrm{MgSO}_{4} .7 \mathrm{H}_{2} \mathrm{O}, 0.200 ; \mathrm{FeSO}_{4} .7 \mathrm{H}_{2} \mathrm{O}, 0.006$; $\mathrm{MoO}_{3}, 0.0005 ; \mathrm{CaSO}_{4} .2 \mathrm{H}_{2} \mathrm{O}, 0.02 ; \mathrm{SrCl}_{2} .6 \mathrm{H}_{2} \mathrm{O}, 0.01 ; \mathrm{NaCl}, 0.01 ; \mathrm{NaHCO}_{3}, 0.05$. De-ionized water was used in the preparation of this medium. The medium was at pH $7 \cdot 8$ before autoclaving (18 lb./sq.in. for $20 \mathrm{~min}$.). When sucrose was added as the carbon source, it was autoclaved (18 lb./sq.in. for $20 \mathrm{~min}$.) in $50 \%(\mathrm{w} / \mathrm{v})$ solutions and added to the medium to give a final concentration of $0.5 \%(\mathrm{w} / \mathrm{v})$. Hereafter, the term 'Nf medium' is used instead of 'nitrogen-free medium'.

ATCC media. The base medium contained (g. $/$.): $\mathrm{K}_{2} \mathrm{HPO}_{4}, \mathbf{1 . 0}$ g.; $\mathrm{MgSO}_{4} .7 \mathrm{H}_{2} \mathrm{O}_{2}$, $0.2 ; \mathrm{NaCl}, 0.2$; $\mathrm{FeSO}_{4} .7 \mathrm{H}_{2} \mathrm{O}$, trace; soil extract, $100 \mathrm{ml}$.; tap water, $900 \mathrm{ml}$. The soil extract was prepared by adding $77 \mathrm{~g}$. of a commercial African violet potting soil and $0.2 \mathrm{~g}$. $\mathrm{Na}_{2} \mathrm{CO}_{3}$ to $200 \mathrm{ml}$. distilled water. The mixture was autoclaved (18 lb./sq.in. for $1 \mathrm{hr}$.) and filtered through a Buchner funnel. The four media prepared from the above stock were: ATCC-1, adjusted to $\mathrm{pH} 8 \cdot 3,2 \%(\mathrm{w} / \mathrm{v})$ mannitol added, autoclaved, final $\mathrm{pH} 7 \cdot 6$; ATCC-2, adjusted to $\mathrm{pH} 6.0,2 \%$ $(\mathrm{w} / \mathrm{v})$ mannitol added, autoclaved; ATCC-3, adjusted to $\mathrm{pH} 6.0,2 \%(\mathrm{w} / \mathrm{v})$ glucose added, autoclaved, ATCC-4, adjusted to $\mathrm{pH} \mathbf{7 \cdot 6}$, autoclaved, sterile glucose to a final concentration $1.0 \%(\mathrm{w} / \mathrm{v})$. All autoclaving was at $18 \mathrm{lb} . / \mathrm{sq} . \mathrm{in}$. for $20 \mathrm{~min}$.

Phages. Ten phages were used in these studies. One phage, designated 'Original' or 'A-11' for these studies, was reported by Monsour et al. 1955; the other nine phages were new isolates made in this laboratory. 
Isolation of phage from soil. One-litre flasks containing $50 \mathrm{ml}$. Nf medium with $0.5 \%(w / v)$ sucrose as carbon source were seeded with $1.0 \mathrm{~g}$. soil and incubated on a shaker at $8^{\circ}$ for 4 days. At this time, the contents of the flask were clarified by centrifugation, passed through a membrane filter (Millipore, 047 mm.) and assayed for phage by the double agar layer technique. The indicator strain for the phage assays was Azotobacter vinelandii $\mathrm{O}$.

Phage assay. Phage dilutions were made in Nf medium minus carbon source, and plaque counts were made by the overlay method (Adams, 1950) modified by Kellogg (1957) for use with azotobacter phage. Approximately $85 \mathrm{ml}$. Nf medium containing $1.8 \%$ agar $(w / v)$ were used for the base layer, and $2.0 \mathrm{ml}$. containing $0.5 \%(w / v)$ agar were used for the semisolid agar layer that contained the mixture of the suspension of bacteria and phage. Unless otherwise stated, both layers of media contained sucrose at a final concentration of $0.5 \%(w / v)$. Incubation was at $\mathbf{8 3}^{\circ}$ for $24 \mathrm{hr}$. or until satisfactory plaque formation was observed (the plates were not inverted).

Preparation of indicator strain. The strain used for the background growth was grown in $15 \mathrm{ml}$. volumes of Nf medium containing $0.5 \%(\mathrm{w} / \mathrm{v})$ sucrose and incubated at $83^{\circ}$ on a shaker for $12-18 \mathrm{hr}$. After growth, the culture was centrifuged at room temperature, the organisms washed, resuspended in de-ionized water and adjusted to a turbidity reading of $\mathbf{8 5}$ units on a Klett-Summerson photoelectric colorimeter (blue filter). Unless otherwise stated, Azotobacter vinelandii $\mathbf{O}$ was used as the indicator strain.

Propagation of phage. For the preparation of stock phage, phages were grown using Arotobacter vinelandii $\mathrm{O}$ as the propagating strain. Organisms were grown in litre flasks containing $100 \mathrm{ml}$. Nf medium $+0.5 \%(w / v)$ sucrose. Incubation was on a shaker at $83^{\circ}$ until a turbidity reading of 85 units on the Klett-Summerson photoelectric colorimeter (blue filter) was obtained. This turbidity represented $8 \times 10^{7}$ viable organisms $/ \mathrm{ml}$. Phages were added to the organisms at a 1:1 ratio of phage:organisms, and the organism + phage mixture allowed to remain static at $\mathbf{8 3}^{\circ}$ for $\mathbf{8 0}$ min. at which time it was placed on a shaker at the same temperature for $7-18 \mathrm{hr}$.

A second method for obtaining phage stocks was used for two phages (A-24, A-41). These phages were assayed by the overlay method and the plate from the highest dilution which showed almost complete lysis was selected. The soft agar layer was scraped from the plate and placed in $7.5 \mathrm{ml}$. Nf media. After overnight extraction at $4^{\circ}$, the agar was removed by filtration through cheesecloth, and the bacterial debris sedimented at low speed in a centrifuge. The supernatant fluid was assayed, and the process repeated until no further increase in phage titre was observed. At this time, a larger quantity of phage stock was obtained by preparing 10-20 plates at the phage dilution which gave complete to partial lysis. Following propagation, phage preparations were stored overnight at $4^{\circ}$ to allow debris to settle out. The supernatant fluids were decanted, centrifuged at $700 \mathrm{rev}$./min. for $30 \mathrm{~min}$. and passed through a membrane filter (Millipore, $047 \mathrm{~mm}$ ). The phage filtrates were stored at $4^{\circ}$.

Preparation and assay of antiphage sera. For the initial series of immunizations, rabbits were immunized subcutaneously with $5 \mathrm{ml}$. phage filtrate at 5-day intervals until a series of six injections had been administered. The animals were then bled 
at either 6 or 15 days following the last injection. Booster immunizations consisted of two $5.0 \mathrm{ml}$. subcutaneous injections given 5 days apart and for the majority of the phages were administered 1 month following the last injection of the initial series. All sera were collected in the usual manner and stored at $-20^{\circ}$ without preservative.

The rates of inactivation of the various azotobacter phages by their homologous and heterologous antisera were determined by the following procedures. All dilutions were made in Nf medium. Stock phages were diluted to contain approximately $10^{5}$ to $10^{6}$ plaque-forming units $/ \mathrm{ml}$. (the term 'plaque-forming units' is hereafter referred to as 'PFU'). The sera were diluted to a concentration determined by preliminary tests which permitted approximately 1-10\% survival of the PFU after sera and phage dilutions were mixed and incubated at $37^{\circ}$ for 5-10 min. Phage and serum dilutions were preheated to $37^{\circ}$ in a water bath. At time zero, 5.0 ml. phage dilution were added to $5.0 \mathrm{ml}$. serum dilution, and at specified time intervals $0.1 \mathrm{ml}$. samples were removed and mixed with $9.9 \mathrm{ml}$. Nf medium. The initial 1/100 dilution was sufficient to stop the neutralizing action of the antisera. Dilutions within the range required were made to detect phage survival by the plaque count method. Plating was done in duplicate by the overlay method in the usual manner. A phage control containing $5 \cdot 0 \mathrm{ml}$. Nf medium instead of immune sera was run simultaneously and served as a basis for determining \% survival of phage. The results of the assays of surviving phage of each neutralization were plotted on a logarithmic scale against time on a linear scale. A straight line was drawn through the points, and the $K$ value determined (Adams, 1959).

Neutralization technique. Cross-neutralization assays with the various azotobacter phages and antiphage sera were carried out in accordance with the following procedures. All antisera were used at a final dilution of 1/200 except antiserum A-41, which was used at a final dilution of $1 / 100$. Three ten-fold serial dilutions were used for each phage and the dilutions were calculated so that the middle dilution would provide approximately $100 \mathrm{PFU} / \mathrm{ml}$. in the final dilution. Dilutions of phage and antisera were made in Nf medium minus carbon source. Equal quantities of the various phage dilutions and antisera dilutions were mixed and incubated in a water bath at $37^{\circ}$ for $30 \mathrm{~min}$. Two controls were run simultaneously: one contained Nf medium instead of antiserum, the second contained normal rabbit serum at the same dilution as the immune sera. Following incubation, the assay tubes were placed in an ice water bath, and samples were plated by the double agar layer method in the usual way. Plaques were counted and a comparison made between the controls and immune sera.

Host specificity assays. A modification of the overlay technique was used in these experiments. Nf medium was used for growth of all strains with the following exceptions: Azotobacter macrocytogenes strains 12334, 12335, 12336, medium ATCC-2; $A$. indicus strains 9037, 9038, 9039, 9450, medium ATCC-3; $A$. chroococcum strain 9048, medium ATCC-4, strain 7499, medium ATCC-1; A. agilis strains 9042, 9570, medium A'TCC-4. Petri plates measuring $14 \mathrm{~cm}$. diam. $\times 2 \mathrm{~cm}$. were used. Approximately 100-150 ml. agar medium was used for the basal layer, and $10 \mathrm{ml}$. was used for the soft agar layer which contained $0.5 \mathrm{ml}$. of a bacterial suspension. Young broth cultures of azotobacter strains were centrifuged, washed, resuspended in water and standardized to a reading of 40 units on the Klett-Summerson 
photoelectric colorimeter (blue filter) with the exception of the $A$. macrocytogenes strains which were standardized to 50 units. The plates were subdivided into 2025 squares, and dilutions of the phages ranging from $1 / 10$ to $1 / 100,000$ were pipetted in $0.02 \mathrm{ml}$. amounts on to the top layer of agar. Following absorption of the phage suspensions, the plates were incubated at $33^{\circ}$ for $18-24 \mathrm{hr}$.; the time depended upon the growth rate of the various strains.

\section{RESULTS}

\section{Isolation of phage from soil}

Preliminary experiments indicated that the natural azotobacter flora present in the soil samples under investigation would serve as the enrichment strains and that addition of laboratory cultures of the bacteria to the culture medium was not necessary. Soil samples were obtained from various geographical localities, and phages were isolated according to the procedures described in the previous section. The results of the isolation experiments are presented in Table 1.

Table 1. Results of azotobacter phage isolations from six different soil samples

\begin{tabular}{|c|c|c|c|c|}
\hline Soil source & Flask no. & $\begin{array}{c}\text { Phage assay } \\
\text { PFU/ml. }\end{array}$ & $\begin{array}{c}\text { No. different } \\
\text { phages } \\
\text { isolated }\end{array}$ & $\begin{array}{c}\text { Present } \\
\text { phage } \\
\text { designation }\end{array}$ \\
\hline Maryland & $\begin{array}{l}\text { MD-1 } \\
\text { MD-2 }\end{array}$ & $\begin{array}{l}1.4 \times 10^{\circ} \\
5.5 \times 10^{\circ}\end{array}$ & $\mathbf{1}$ & A-22 \\
\hline Ohio & $\begin{array}{l}\text { OH-1 } \\
\text { OH-2 }\end{array}$ & $\begin{array}{l}9 \times 10^{8} \\
1 \times 10^{7}\end{array}$ & 2 & $\begin{array}{l}\text { A-12 } \\
\text { A-24 }\end{array}$ \\
\hline Texas & SA & $1.2 \times 10^{7}$ & 2 & $\begin{array}{l}\text { A-14 } \\
\text { A-23 }\end{array}$ \\
\hline Texas & VA & $3.7 \times 10^{7}$ & 2 & $\begin{array}{l}\text { A-13 } \\
\text { A-21 }\end{array}$ \\
\hline Texas & $\theta$ & $1 \times 10^{5}$ & 1 & $A-41$ \\
\hline Texas & FB & $1 \times 10^{8}$ & 1 & A-31 \\
\hline
\end{tabular}

By these procedures, phage titres ranging from $10^{5}$ to $10^{9} \mathrm{PFU} / \mathrm{ml}$. were obtained, and on the basis of plaque morphology, nine different phages were isolated and purified by further single plaque selection. From three of the soil samples two distinct phage isolates were made, whereas the remaining samples appeared to have homogeneous plaques.

\section{Plaque morphology}

In the selection of plaques during the purification of azotobacter phages by singleplaque selection, an attempt was made to select plaques of extreme size, for example, minute or large; plaques with small clear areas and wide turbid halos; or plaques with large clear areas and small halos. Photographs of the plaques produced by the azotobacter phages are shown in Pl. 1, figs. A-I, and a description of the plaque size is presented in Table 2.

The host strain for these studies was Azotobacter vinelandii $\mathbf{O}$, and the plating conditions were the same as those previously described. The plaques consisted of a central clear area surrounded by a halo and ranged in size from 1 to $7 \mathrm{~mm}$. in diameter. This halo was present even in very small plaques in which the central 
Table 2. Plaque size of asotobacter phages with Azotobacter vinelandii 0 as the indicator strain

$\begin{array}{cccc}\text { Phage } & \begin{array}{c}\text { Plaque } \\ \text { diameter } \\ (\mathbf{m m})\end{array} & \begin{array}{c}\text { Halo } \\ \text { diameter } \\ (\mathbf{m m} .)\end{array} & \begin{array}{c}\text { Diameter of } \\ \text { clear area of } \\ \text { lygis (mm.) }\end{array} \\ \text { A-11 } & 1-4 & 0 \cdot 5-1 \cdot 5 & 0 \cdot 5 \\ \text { A-12 } & 1 & <1 & 1 \\ \text { A-18 } & 4 & 1 \cdot 5 & 1 \\ \text { A-14 } & 1-2 & 0 \cdot 5 & 1 \\ \text { A-21 } & 6-7 & 1-1 \cdot 5 & 3 \cdot 5-4 \\ \text { A-22 } & \mathbf{3 - 5} & 1-1 \cdot 5 & 2 \\ \text { A-23 } & 3-5 & 1 & 2 \cdot 5-3 \\ \text { A-24 } & 3 & 1 & 1 \\ \text { A-81 } & 4 & 1 & 2 \\ \text { A-41 } & 3-4 & 1 & 0.5\end{array}$

clear area was not very apparent. The plaques observed with these phages were of four types: (1) minute, represented by A-12 and A-14; (2) small central clear area with wide halo, represented by A-13 and A-11; (3) large central clear area with narrow halo, represented by A-21, A-22, A-28 and A-81; (4) large central clear area with irregular or 'frayed' halo, represented by A-41. At early readings this plaque no. 4 gave the appearance of not having a halo; however, when the plates were refrigerated overnight, a more pronounced halo was observed. This observation was also true for the minute plaques of phages A-12 and A-14.

\section{Propagation of phages}

Although optimum conditions for maximum phage titre were not determined, high-titre phage stocks were prepared from the original phage (A-11) and eight of the newly isolated phages according to the methods described in the previous section. The results of a propagation experiment are presented in Table 3.

Table 3. Preparation of phage stocks with Azotobacter vinelandii $\mathrm{O}$ as the propagating strain

\begin{tabular}{|c|c|c|c|c|c|c|}
\hline Phage & PFU/ml. & $\begin{array}{c}\text { Phage } \\
\text { added } \\
\text { (ml.) }\end{array}$ & $\begin{array}{l}\text { Azoto- } \\
\text { bacters* } \\
\text { added } \\
\text { (ml.) }\end{array}$ & $\begin{array}{l}\text { PFU/mi. in } \\
\text { flask before } \\
\text { incubation }\end{array}$ & $\begin{array}{c}\text { Time on } \\
\text { shaker } \\
\text { (hr.) }\end{array}$ & $\begin{array}{c}\text { PFU } / \text { ml. after } \\
\text { incubation }\end{array}$ \\
\hline $\begin{array}{l}A-11 \\
A-12 \\
A-18 \\
A-14 \\
A-21 \\
A-22 \\
A-28 \\
A-31\end{array}$ & $\begin{array}{c}1.7 \times 10^{\circ} \\
1.8 \times 10^{\circ} \\
1.8 \times 10^{9} \\
8.2 \times 10^{\circ} \\
1.5 \times 10^{\circ} \\
1.6 \times 10^{10} \\
1 \times 10^{\circ} \\
6 \times 10^{\circ}\end{array}$ & $\begin{array}{l}2 \\
2 \\
2 \\
1 \\
\mathbf{3} \\
0 \cdot 2 \\
\mathbf{8} \\
\mathbf{1}\end{array}$ & $\begin{array}{l}98 \\
98 \\
98 \\
99 \\
97 \\
99 \cdot 8 \\
97 \\
99\end{array}$ & $\begin{array}{r}\mathbf{8 . 4} \times 10^{7} \\
3 \times 10^{7} \\
3 \times 10^{7} \\
3 \times 10^{7} \\
3 \times 10^{7} \\
3 \times 10^{7} \\
\mathbf{3} \times 10^{7} \\
6 \times 10^{7}\end{array}$ & $\begin{array}{r}18 \\
13 \\
7 \\
7 \\
7 \\
18 \\
7 \\
13\end{array}$ & $\begin{aligned} 1 & \times 10^{9} \\
\mathbf{8} & \times 10^{8} \\
1.5 & \times 10^{9} \\
1 & \times 10^{9} \\
1.3 & \times 10^{9} \\
5 & \times 10^{10} \\
1.3 & \times \mathbf{1 0}^{9} \\
\mathbf{4} & \times 10^{9}\end{aligned}$ \\
\hline
\end{tabular}

The Azotobacter vinelandii strain $O$ was used at a concentration of $3 \times 10^{7}$ viable organisms/ml. and the ratio phage:organisms at the start of the experiment was approximately $1: 1$. For the majority of the phages, final titre of $10^{\circ} \mathrm{PFU} / \mathrm{ml}$. was 
achieved. Four of the phage preparations showed complete lysis of the bacterial culture after incubation on the shaker for $c .7 \mathrm{hr}$.; for the remaining preparations an arbitrary incubation time of $18 \mathrm{hr}$. was selected. With the majority of the azotobacter phages a considerable amount of bacterial debris remained after lysis.

Two of the azotobacter phages (A-24, A-41) were not successfully propagated according to the above methods; therefore a modification of the agar layer technique was used. By these procedures, the highest titres obtained for phages A-24 and A-41 were $5 \times 10^{8}$ and $5 \times 10^{7} \mathrm{PFU} / \mathrm{ml}$, respectively. All phage preparations appeared stable following Millipore filtration and storage at $4^{\circ}$ with the exception of phage A-11; however, non-filtered preparations of this phage appeared to be stable.

Table 4. Cross-neutralization by representative antisera against various
azotobacter phages

\begin{tabular}{|c|c|c|c|c|c|c|c|c|c|c|}
\hline \multirow{2}{*}{$\begin{array}{l}\text { Anti- } \\
\text { sera }\end{array}$} & \multicolumn{10}{|c|}{ Phages } \\
\hline & A-11 & A-12 & A-18 & A-14 & A-21 & A-22 & A-23 & A-24 & A-31 & $A-41$ \\
\hline $\begin{array}{l}\text { A-11 } \\
\text { A-12 }\end{array}$ & + & + & + & + & $\overline{-}$ & $=$ & - & - & - & - \\
\hline A-13 & + & + & + & + & - & - & - & - & I & $\overline{-}$ \\
\hline A-14 & + & + & + & + & - & - & - & - & - & - \\
\hline A-21 & - & - & - & - & + & + & + & + & - & - \\
\hline A-22 & - & - & - & - & + & + & + & + & - & - \\
\hline A-23 & - & - & - & - & + & + & + & + & - & - \\
\hline $\mathbf{A - 3 1}$ & - & - & - & - & - & - & - & - & + & - \\
\hline $\mathbf{A}-\mathbf{4 1}$ & - & - & - & - & - & - & - & - & - & + \\
\hline $\begin{array}{c}\text { Normal } \\
\text { serum }\end{array}$ & - & - & - & - & - & - & - & - & - & - \\
\hline
\end{tabular}

$+=$ neutralization; $-=$ no neutralization. All antisera and the normal serum were used at final dilution 1/200, except antiserum A-41 which was used at final dilution 1/100.

\section{Serological classification}

The cross-neutralization data (Table 4) indicated that the phages formed four main serological groups; groups one and two contained four phages each, and groups three and four contained one phage each. Although antiserum against phage A-24 was not prepared, this phage was neutralized by the available group two antisera. On the basis of these data, the following serological groups for the azotobacter phages are proposed and will be referred to in subsequent discussions: group I (phages A-11, A-12, A-13, A-14); group II (phages A-21, A-22, A-23, A-24); group III (phage A-81); group IV (phage A-41).

\section{Kinetics of phage neutralization}

The neutralization rate constants of the various phages by their respective homologous antisera are presented in Table 5 . Since the $K$ value is a characteristic of the particular lot of serum used, the serum data have been included for reference purposes. The phages were neutralized by dilutions of homologous antisera ranging from $1 / 500$ to $1 / 5000$, and the $K$ values ranged from 18 to 1917. As reported for other phage systems, the azotobacter phages differed greatly with respect to their rates of reaction with homologous antisera. As a group, the phages belonging to 
Table 5. Neutralization rate constants $(K)$ of azotobacter phages with homologous antisera

\begin{tabular}{|c|c|c|c|c|}
\hline Phage & $\begin{array}{l}\text { Final serum } \\
\text { dilution }\end{array}$ & Serum date & PFU/ml. & $\mathbf{K}$ \\
\hline A-14 & $1 / 5000$ & $8 / 26 / 58$ & $7.8 \times 10^{6}$ & 1917 \\
\hline A-21 & $1 / 6000$ & $8 / 26 / 58$ & $8.3 \times 10^{6}$ & 1642 \\
\hline A-22 & $1 / 5000$ & $2 / 8 / 58^{*}$ & $8.9 \times 10^{6}$ & 1584 \\
\hline A-28 & $1 / 2000$ & $8 / 26 / 58$ & $8.3 \times 10^{6}$ & 742 \\
\hline A-81 & $1 / 1000$ & $11 / 4 / 57$ & $8.0 \times 10^{6}$ & 575 \\
\hline A-18 & $1 / 2000$ & $8 / 26 / 58$ & $3.7 \times 10^{6}$ & $46 \mathrm{C}$ \\
\hline A-11 & $1 / 1000$ & $10 / 21 / 57^{*}$ & $1.7 \times 10^{6}$ & 32 \\
\hline A-12 & $1 / 200$ & $8 / 26 / 58$ & $5.5 \times 10^{6}$ & 115 \\
\hline$A-41$ & $1 / 150$ & $9 / 27 / 58$ & $1.3 \times 10^{5}$ & 18 \\
\hline
\end{tabular}

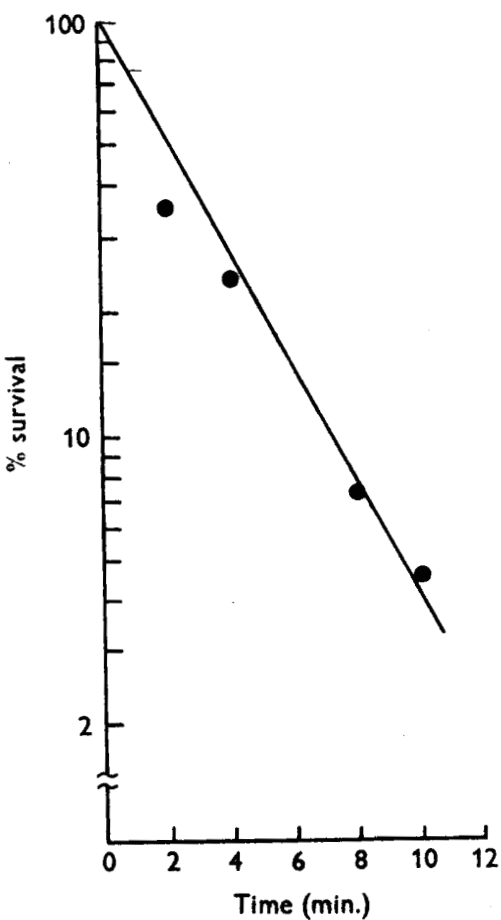

Fig. 1

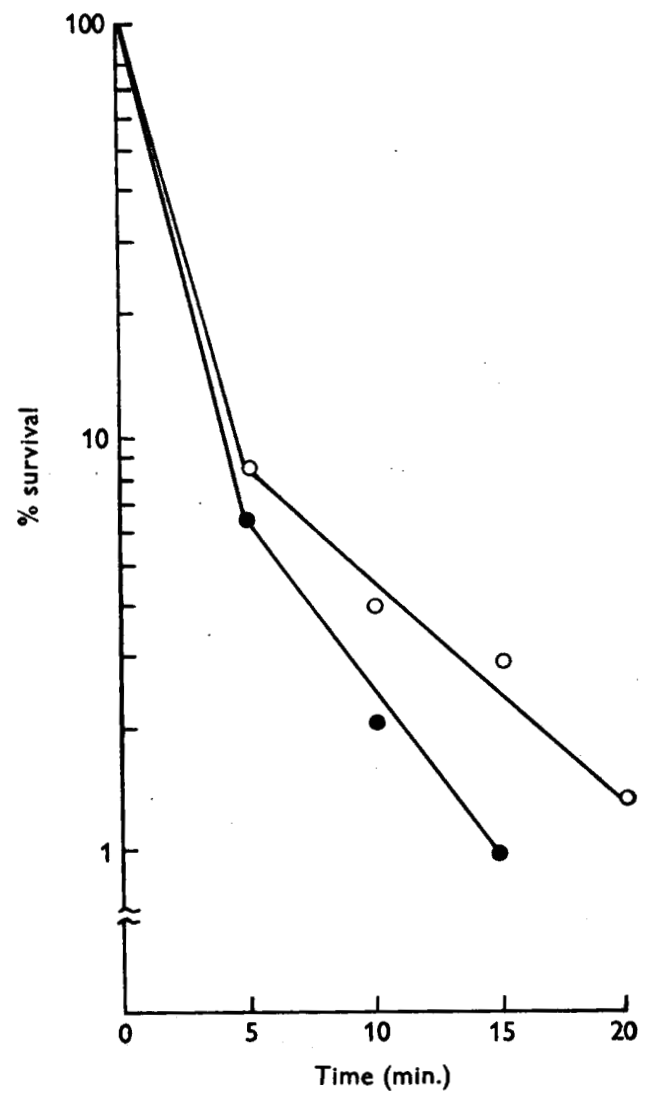

Fig. 2

Fig. 1. Rate of inactivation of phage A-11 by homologous antiserum (diluted 1/1000).

Fig. 2. Rates of inactivation of phage A-12 by homologous antiserum. The antiserum was diluted 1/200. O, Expt. 1; O, Expt. 2. 
serological group II were among the better antigens, since their antisera showed relatively high $K$ values. The high $K$ value for serum $A-14$ indicated phage A-14 acted as a much better immunizing antigen than the other phages (A-11, A-12, A-18) of serological group I. The low $K$ value observed with serum $A-41$ may be attributed to the relatively low concentration of phage used in the immunizing antigen.

The neutralization curves from which the $K$ values were calculated are presented in Figs. 1-7. The values for sera A-21, A-22 and A-23 were obtained from the curves shown for the homologous neutralizations shown in Figs. 5-7.

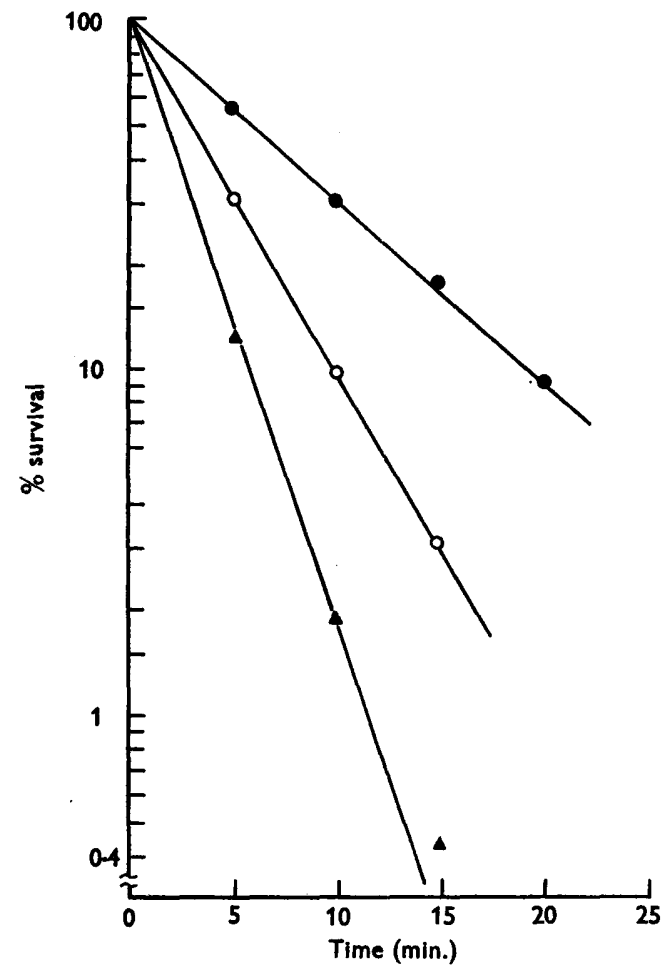

Fig. 3

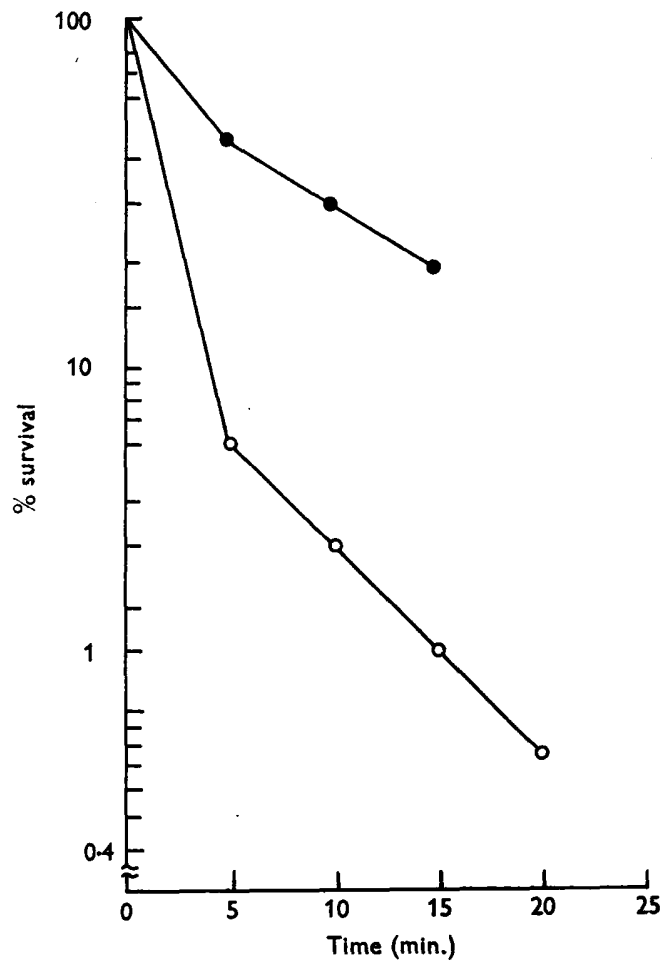

Fig. 4

Fig. 3. Rates of inactivation of phages A-13, A-14 and A-41 by homologous antisera. The antisera were diluted $1 / 2000$ for $A-13,1 / 5000$ for $A-14$ and $1 / 150$ for $A-41$. O, Phage, A-13; $A$, phage A-14; O, phage A-41.

Fig. 4. Rates of inactivation of phage A-31 by homologous antisera. For Expt. 1, the phage was preparation $3 / 17 / 59$ and the antiserum was lot number $1 / 11 / 58$. The antiserum was diluted $1 / 2000$. For Expt. 2, the phage was preparation $6 / 23 / 58$ and the antiserum was number 4 of 11/5/57. The antiserum was diluted 1/1000. Serum 1/11/58; O, serum 11/5/57.

With phages A-12 and A-31 neutralization by homologous antisera did not follow first-order reactions. Figure 2 shows two separate neutralization curves obtained for phage A-12 with its homologous antiserum. Neutralization of phage proceeded rapidly to $c .96-98 \%$ inactivation of phage and then slowed down rather abruptly. Figure 4 shows that inactivation of phage A-31 behaved similarly. With phage A-31 
both the pooled sera (date $1 / 11 / 58$ ) and the individual serum from rabbit 4 (date $11 / 5 / 57$ ) showed this peculiarity. Also, the use of a different phage preparation in the experiment did not alter the shape of the curve. It should be noted that for these two phage serum systems the initial slopes of the neutralization curves were used to calculate $K$ values to serve as an estimate of the relative neutralizing potencies of the sera.

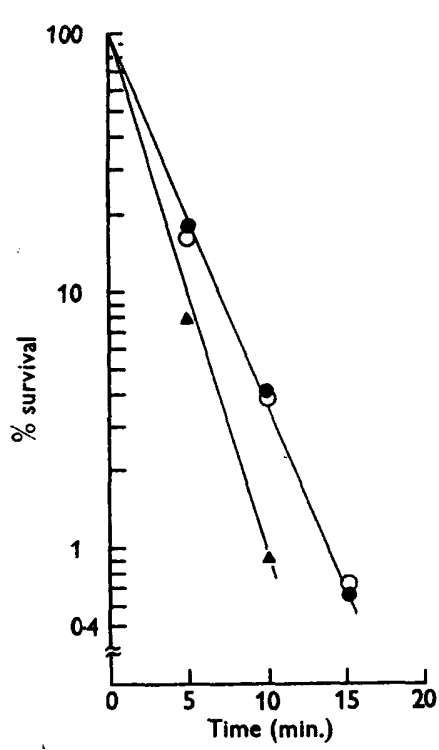

Fig. 5

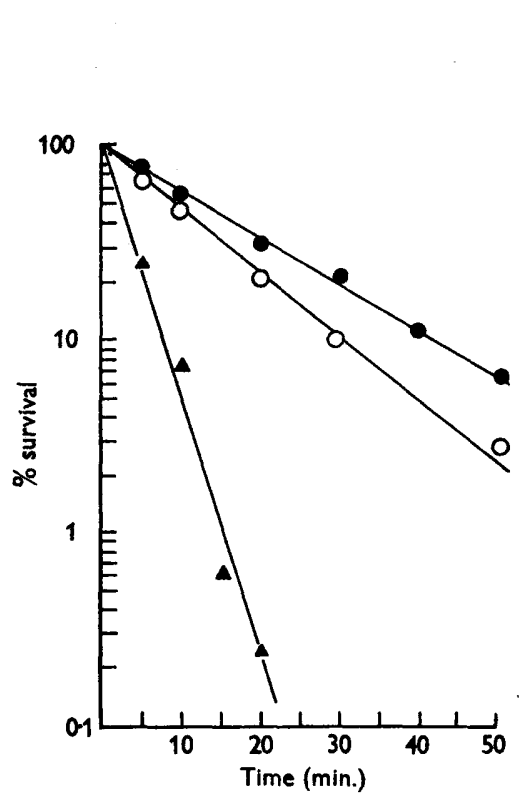

Fig. 6

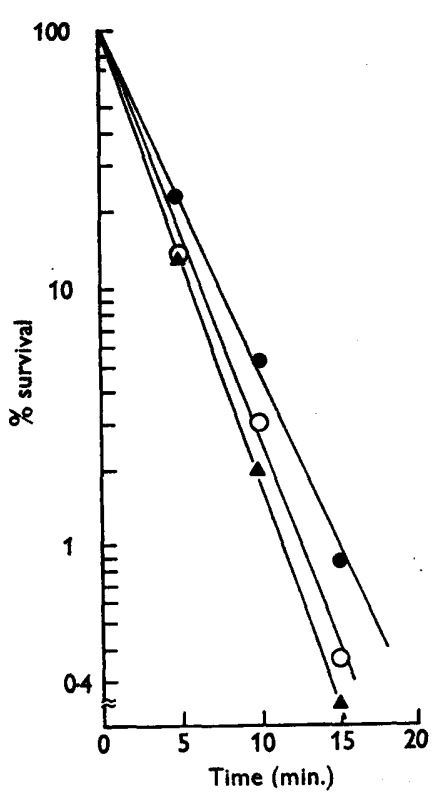

Fig.7

Fig. 5. Rates of inactivation of phages A-21, A-22 and A-23 by A-21 antiserum. The serum was diluted $1 / 5000$ for phages $A-21$ and $A-23$ and $1 / 1000$ for phage $A-22$., Phage A-21; $\triangle$, phage A-22; O, phage A-23.

Fig. 6. Rates of inactivation of phages A-21, A-22 and A-23 by A-22 antiserum. The antiserum was diluted $1 / 5000$ for the homologous phage and $1 / 3000$ for the heterologous phages.

Fig. 7. Rates of inactivation of phages A-21, A-22 and A-23 by A-23 antiserum. The antiserum was diluted $1 / 2000$ for the homologous phage and for phage A-21, and 1/300 for phage A-22.

In order to determine the degree of relatedness among the phages of serological group II, neutralization curves were determined for three of the phages using homologous and heterologous antisera (Figs. 5-7). The $\mathbf{K}$ values for the homologous and reciprocal neutralizations are presented in Table 6. The rate of neutralization was greater with homologous phage and antiserum than with the heterologous system, except with antiserum 21 where the neutralization rates for phages A-21 and A-23 were the same. These data indicated that antigenically phages A-21 and A-23 were either very closely related or identical. This conclusion was substantiated with antisera A-22 and A-28. In addition, these data showed that the degree of relatedness of phage $\mathbf{A - 2 2}$ to the other two phages was more distant than the relationship between phages A-21 and A-23. 
Table 6. Neutralization rate constants $(K)$ of representative group II antisera* against group II phages

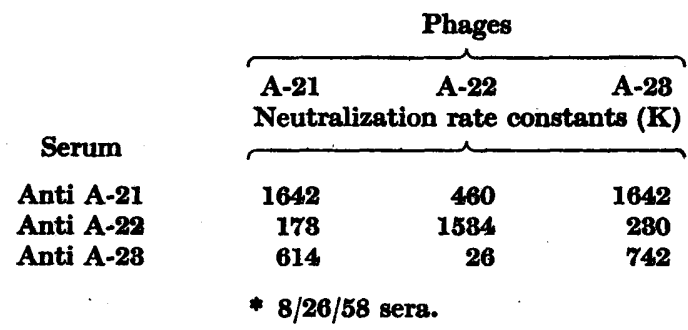

Preliminary investigations have been conducted on the degree of relatedness among the serological group I phages. Kinetic curves of neutralization using heterologous antiphage sera were not determined for these phage + serum systems; instead, an arbitrary end-point was used, namely the $\%$ of the initial phage population which survived after contact with serum at a stated concentration and for a specified time. The procedures were essentially the same as those described for the kinetic studies of phage neutralization except that only one time period was used to assay for phage survival. The time of assay varied with the antisera and was as follows: 5 min. for serum A-12, $10 \mathrm{~min}$. for serum A-18, $6 \mathrm{~min}$. for serum A-14. The final dilutions of sera were $1 / 200$ for A-12, 1/2000 for A-18 and 1/5000 for A-14. All phages were diluted to contain approximately $10^{5} \mathrm{PFU} / \mathrm{ml}$.

\section{Table 7. Neutralization of serological group I phages by homologous and heterologous antisera}

\begin{tabular}{|c|c|c|c|}
\hline & & Phages & \\
\hline & A-12 & A-13 & A-14 \\
\hline Serum & & $\mathrm{val}$ of & \\
\hline Anti A-12 & 5 & 17 & $\mathbf{3}$ \\
\hline Anti A-18 & 75 & 41 & 57 \\
\hline Anti A-14 & 14 & 39 & 14 \\
\hline
\end{tabular}

Table 7 shows the \% survival of serological group I phages after neutralization by homologous and heterologous antisera. With serum A-12, \% survival was essentially the same for phages A-12 and A-14 and greater for phage A-18. The results obtained with serum A-14 were similar to those observed with serum A-12. Serum A-13 inactivated its homologous phage more rapidly than either of the heterologous phages. These data indicated a close antigenic relationship between phages A-12 and A-14. In other experiments, not shown here, serum A-13 neutralized phages A-11 and A-13 at approximately the same rate, indicating a close relationship between these two phages. With phage A-11 it was important to use a newly produced phage stock. Cell-free filtrates of this phage lost their infectivity rapidly upon storage and older preparations sometimes showed anomalous neutralization patterns. 


\section{Host specificity assays}

Host specificity assays were undertaken for the purpose of defining further the identity of the phages and also to ascertain the range of host infectiveness. Two of the phages, A-21 and A-28, were shown to be either identical or closely related by serological methods and it was of interest to compare their host-range specificity reactions. These data are presented in Table 8 and it may be observed that both phages gave identical results. Since it appeared that these two phages were identical, further studies on host-range specificity included only one of these phages, namely A-21.

Table 8. Comparison of host-specificity reactions for phages A-21 and A-23

\begin{tabular}{|c|c|c|c|c|c|}
\hline \multirow{3}{*}{$\begin{array}{l}\text { Strains } \\
\text { A. vinelandii }\end{array}$} & \multicolumn{2}{|c|}{ Phages } & \multirow[b]{2}{*}{ Strains } & \multicolumn{2}{|c|}{ Phages } \\
\hline & $\begin{array}{c}\text { A-21 } \\
\text { lytic }\end{array}$ & $\begin{array}{l}\text { A-28 } \\
\text { ivity }\end{array}$ & & $\begin{array}{l}\text { A-21 } \\
\text { lytic }\end{array}$ & $\begin{array}{l}\text { A-23 } \\
\text { vity }\end{array}$ \\
\hline & $\longrightarrow$ & $\longrightarrow$ & A. chroococcum & & \\
\hline $\mathbf{0}$ & 5 & $5+$ & $\mathbf{A}$ & $2^{*}$ & $2 *$ \\
\hline 478 & 5 & 5 & $\mathbf{S}$ & 5 & 4 \\
\hline 7487 & $1 *$ & $1^{*}$ & $\mathbf{F}$ & - & - \\
\hline 7489 & $2^{*}$ & $2^{*}$ & $\mathbf{J}$ & - & - \\
\hline 7492 & 2* & $2^{*}$ & $\mathbf{E}$ & $\mathbf{5}$ & 5 \\
\hline 8046 & 3* & $\mathbf{3}^{*}$ & $\mathbf{B}$ & - & - \\
\hline 9047 & $1 *$ & $2^{*}$ & 9835 & $\mathbf{5}$ & 5 \\
\hline 12837 & $\mathbf{3}$ & 8 & 9544 & 4 & 4 \\
\hline 7496 & $2^{*}$ & $2^{*}$ & 12981 & - & - \\
\hline 9104 & 5 & 5 & & & \\
\hline $\mathbf{K}$ & 4 & 4 & & & \\
\hline
\end{tabular}

Table 9 shows the lytic action of eight phages for 12 strains designated $A$ zotobacter vinelandii. All strains, except 7484, were lysed by one or more of the phages. The strain not lysed by the phages appeared to be a typical member of this species. The phages classified as serological group I (A-11 to A-14), showed identical

Table 9. Lytic action of phages for Azotobacter vinelandii strains

\begin{tabular}{|c|c|c|c|c|c|c|c|c|}
\hline \multirow{2}{*}{$\begin{array}{l}\text { A. vinelandii } \\
\text { strains }\end{array}$} & \multicolumn{8}{|c|}{ Phages } \\
\hline & A-11 & A-12 & A-13 & A-14 & A-21 & A-22 & A-31 & A-4II \\
\hline o & $5 \dagger$ & 5 & $\mathbf{5}$ & 5 & 5 & 5 & 5 & 5 \\
\hline $\mathbf{4 7 8}$ & 5 & 5 & 5 & 5 & 5 & $\mathbf{5}$ & 5 & 5 \\
\hline 7487 & 2 & 5 & 5 & 4 & $1^{*}$ & - & $\mathbf{2}^{*}$ & $1 *$ \\
\hline 7489 & 8 & 4 & 5 & 4 & $2^{*}$ & - & $2^{*}$ & $1 *$ \\
\hline 7492 & 8 & $\mathbf{3}$ & 5 & 5 & $2^{*}$ & - & $2^{*}$ & $1 *$ \\
\hline 9046 & $\mathbf{2}^{*}$ & $2^{*}$ & $5^{*}$ & $2^{*}$ & $\mathbf{3}^{*}$ & $2 *$ & $4^{*}$ & 5 \\
\hline 9047 & 4 & 3 & 5 & 5 & $1^{*}$ & - & $2^{*}$ & $1 *$ \\
\hline 12837 & $2^{*}$ & $2^{*}$ & $2^{*}$ & $5^{*}$ & 8 & 5 & 2 & - \\
\hline 7496 & 4 & $\mathbf{3}^{*}$ & 5 & $\mathbf{8}$ & $2^{*}$ & $1^{*}$ & $\mathbf{3}^{*}$ & 2* \\
\hline 9104 & 5 & $\mathbf{3}$ & 4 & $\mathbf{5}$ & 5 & 5 & 5 & 5 \\
\hline $\mathbf{K}$ & 5 & $\mathbf{2}^{*}$ & 5 & 4 & 4 & 5 & 5 & 5 \\
\hline 7484 & - & - & - & - & - & - & - & 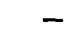 \\
\hline
\end{tabular}

+ Number 5 means lytic action at $1 / 10^{5}$ dilution, etc.

* Indicates plaques were not observed. - indicates no lytic action. 
host range specificity with the exception of phage A-12 which did not form plaques on strains $K$ and 7496. The phages of serological group II, A-21 and A-22, showed identical host range specificity. The lack of lytic action of phage A-22 on several strains was not considered a major difference, since plaque formation with phage A-21 was not observed on the same strains. In addition, the phages of serological group I appeared to be more specific for the $A$. vinelandii strains than the phages of serological group II. One strain, 12837, was not lysed by any phage of group I but by both members of group II. Phage A-31, the only member of serological group III, showed plaque formation on the same five strains identified with serological group II phages. Phage 41, the only member of serological group IV, differed from the other three groups, and especially from group III, by formation of plaques on strain 9046 and its lack of lytic action on strain 12837. It may be noted that phage A-41 was the only phage to show plaque formation on strain 9046 .

Table 10. Lytic action of phages for Azotobacter chroococcum strains

\begin{tabular}{|c|c|c|c|c|c|c|c|c|}
\hline \multirow{2}{*}{$\begin{array}{l}\text { A. chroococcum } \\
\text { strains }\end{array}$} & \multicolumn{8}{|c|}{ Phages } \\
\hline & A-11 & A-12 & A-I8 & A-14 & A-21 & A-22 & A-31 & $A-41$ \\
\hline 9335 & $4 \dagger$ & 5 & 5 & 5 & 5 & 2 & $\mathbf{5}$ & $\mathbf{1}$ \\
\hline 7493 & 5 & 5 & 5 & 5 & 5 & 4 & 5 & 2 \\
\hline 0043 & 5 & 5 & 5 & $\mathbf{5}$ & $\mathbf{3}$ & $\mathbf{3}$ & $\mathbf{3}^{*}$ & $1 *$ \\
\hline 7491 & $1^{*}$ & $\mathbf{3}$ & 5 & - & 5 & 4 & 1 & $\mathbf{I}$ \\
\hline 9544 & $\mathbf{2}^{*}$ & $2^{*}$ & $\mathbf{3}^{*}$ & $2^{*}$ & 4 & 5 & 5 & 5 \\
\hline 7486 & $\mathbf{3}^{*}$ & 4 & 5 & $\mathbf{2}^{*}$ & 5 & 5 & 4 & 3 \\
\hline 7490 & $1 *$ & $2^{*}$ & 4 & 5 & 4 & 4 & 5 & 4 \\
\hline 9045 & $2^{*}$ & 4 & 5 & \pm & 5 & 4 & 4 & 4 \\
\hline 4412 & 4 & 4 & 5 & 4 & 5 & 5 & 5 & 1 \\
\hline 7499 & \pm & \pm & 5 & $1 *$ & - & - & 5 & - \\
\hline 8049 & - & - & - & - & - & - & $2^{*}$ & 4 \\
\hline 7498 & - & - & - & - & - & - & $2^{*}$ & - \\
\hline 7488 & - & $2^{*}$ & $\mathbf{3}^{*}$ & $2^{*}$ & $2^{*}$ & - & $4^{*}$ & - \\
\hline $\mathbf{A}$ & $1 *$ & - & $2^{*}$ & $1 *$ & 2* & $2^{*}$ & $2^{*}$ & - \\
\hline $\mathbf{S}$ & - & - & - & - & 5 & 1 & - & 5 \\
\hline $\mathbf{F}$ & - & - & - & - & - & - & $2^{*}$ & 5 \\
\hline $\mathbf{J}$ & - & - & \pm & - & - & - & $\mathbf{3}^{*}$ & - \\
\hline $\mathbf{E}$ & 4 & 4 & 5 & 5 & 5 & 5 & $2^{*}$ & \pm \\
\hline $\mathbf{B}$ & - & - & \pm & - & - & $2^{*}$ & - & \pm \\
\hline C & - & - & \pm & - & - & $2^{*}$ & - & \pm \\
\hline
\end{tabular}

+ Number 4 means lytic action at $1 / 10^{4}$ dilution, etc.

* Indicates plaques were not observed. \pm means questionable lytic action. - indicates no lytic action. Strains 480, 7497, 0048, 9051 and 12981 showed negative reactions with all phages; strain 9044 was not tested.

Table 10 shows the lytic action of eight phages for 25 strains of Azotobacter chroococcum. Five of these strains, listed in the notes beneath Table 10, showed negative reactions with all phages. Six additional strains showed non-specific lysis; that is, plaque formation was not observed. With the $\boldsymbol{A}$. chroococcum strains, the problem of rapid growth and abundant slime production was encountered and plaque formation might \have been missed. For example, strain $F$ did not show plaque formation after incubation for $20 \mathrm{hr}$. at $33^{\circ}$. However, when the plates remained at room temperature during the next $12 \mathrm{hr}$, plaque formation was observed at c. $28 \mathrm{hr}$., but plaques were covered over by the growth of organism and slime formation at c. $32 \mathrm{hr}$. 
These data show that c. $50 \%$ of the Azotobacter chroococcum strains tested were sensitive to one or more of the phages. The phages A-21 and A-22 (serological group II) had identical host range specificity. Phage A-21 appeared to show greater virulence for strain $S$ than did phage A-22; therefore strains could be used to distinguish between or to identify these phages. Whereas the phages of serological groups II and III showed identical host-range specificity with the $A$. vinelandii strains, a few differences were noted among the $A$. chroococcum strains, namely strains 9043 and 7499. Phage A-4I (group IV) was the only phage to show plaque formation with strains $F$ and 9049 . The phages of serological group I showed a few differences. The lack of observed plaque formation with these phages could be due to a combination of poor plaque morphology shown by these phages and the slimy, rapid growth of the strains. Further testing is warranted to determine whether these differences are valid.

A summary of the host-range specificity reactions is presented in Table 11. Only those lytic reactions where plaque formation was observed were included. None of the phages lysed any of the six strains designated Azotobacter agilis, the three strains of $\boldsymbol{A}$. macrocytogenes or the two strains of $A$. insigne. Phage sensitivity of the $\boldsymbol{A}$. indicus strains was difficult to assess because of their slow growth and copious formation of gummy material. However, preliminary studies indicated that these strains were not lysed by any of the phages.

Table 11. Summary of host-specificity reactions of azotobacter phages.

\begin{tabular}{|c|c|c|c|c|c|c|c|c|c|c|}
\hline \multirow[b]{2}{*}{ Azotobacter strains } & \multirow{2}{*}{$\begin{array}{l}\text { No. of } \\
\text { strains } \\
\text { tested }\end{array}$} & \multicolumn{8}{|c|}{ Number of strains lysed by phages* } & \multirow{2}{*}{$\begin{array}{l}\text { No. of } \\
\text { strains not } \\
\text { lysed by } \\
\text { any phage }\end{array}$} \\
\hline & & A-11 & A-12 & A-13 & A-14 & A-21 & A-22 & A-31 & $A-41$ & \\
\hline A. vinelandii & 12 & 9 & 7 & 9 & 9 & 5 & 5 & 5 & 5 & 1 \\
\hline A. chroococcum & 25 & 5 & 8 & 10 & 6 & 11 & 11 & 9 & 11 & 11 \\
\hline A. agilis & 6 & 0 & 0 & 0 & $\mathbf{0}$ & 0 & $\mathbf{0}$ & $\mathbf{0}$ & o & 6 \\
\hline A. macrocytogenes & $\mathbf{3}$ & 0 & 0 & o & 0 & o & $\mathbf{0}$ & $\mathbf{0}$ & o & $\mathbf{3}$ \\
\hline A. insigne & $\mathbf{2}$ & 0 & $\mathbf{0}$ & 0 & 0 & $\mathbf{0}$ & $\mathbf{0}$ & $\mathbf{0}$ & $\mathbf{0}$ & 2 \\
\hline $\begin{array}{l}\text { No. of strains tested } \\
\text { No. of strains lysed }\end{array}$ & $\begin{array}{r}48 \\
.\end{array}$ & $\dot{14}$ & $\dot{15}$ & $\dot{19}$ & $\dot{15}$ & $1 \dot{6}$ & $1 \dot{6}$ & $\dot{14}$ & 16 & . \\
\hline
\end{tabular}

* Only lytic reactions where plaque formation was observed are included.

\section{DISCUSSION}

The methods described for the isolation of the azotobacter phages are of special interest since they utilized the natural azotobacter flora for the enrichment strain rather than the usual addition of bacterial cultures. Although the majority of the soil samples were from various parts of Texas, phage isolates were made from Ohio and Maryland soils, indicating that the azotobacter phages are not confined to any particular geographical area of the United States. The fact that the phages from the Ohio and Maryland soils were antigenically related to phages isolated previously from Texas soils may indicate that the number of serological groups is not great. The four serological groups found thus far for the azotobacter phages are comparable to the number of groups reported for other phage systems.

The plaque morphology observed with the azotobacter phages differed markedly from that seen with the coli phages and many other phage systems; however, it 
resembled most closely the plaques formed by phage $\mathbf{K}$ phich lyses Klebsiella pneumoniae type 2 (Park, 1956). The plaques formed by phage $K p$ were surrounded by translucent halos which gradually increased in diameter over the course of a week. It was demonstrated that a diffusible enzyme was liberated during lysis of the infected host cell, and that the enzyme was responsible for the large spreading halo that surrounded the phage plaques (Park, 1956; Adams \& Park, 1956). It was believed that the enzyme decreased the viscosity of the capsular polysaccharide and stripped it from the surface of the bacterium, thus permitting the phage to penetrate the host cell surface.

The azotobacter phages produce plaques with halos, and since the Arotobacter vinelandii $\mathbf{O}$ organisms are capsulated, it is possible that a similar enzyme is present in the azotobacter + phage system and might account for the observed plaque morphology.

The most widely applied of the taxonomic criteria recommended for defining the species category in bacteriophages is serological relationship (Adams, 1959). Therefore primary emphasis was placed on serology in classifying the azotobacter phages. Cross-neutralization assays indicated four serological groups for the 10 azotobacter phages in the present collection. These groups were designated I, II, III and IV. The individual phages were given numbers preceded by the letter $A$ which stands for the genus Azotobacter. We propose that the phages within a serological group be assigned numbers in the following manner: 11-19 for group I, 21-29 for group II, 81-89 for group III, and 41-49 for group IV. The purpose of using this range of numbers is to permit the incorporation of future phage isolates into any one of the present serological groups. In addition, it allows for inclusion of new serological groups (V, VI, etc.).

The kinetic studies on neutralization of phage with homologous and heterologous antisera indicate that phages A-21 and 23 in serological group II are identical or very closely related. These two phages are similar by plaque morphology and showed identical host-range specificities. If future investigations on additional classification criteria substantiate these findings, it is recommended that one of these two phages be dropped from the present series.

With phages A-12 and A-81 neutralization by homologous antisera did not follow first-order kinetics; however, such anomalous neutralization behaviour has not been uncommon with other phage systems. Andrews \& Elford (1983) noted that neutralization of their phages proceeded rapidly until 90-99\% of the phage was inactivated and then slowed rather abruptly. They demonstrated that this phenomenon was not due to exhaustion of antibody since upon removal of phage the remaining serum was still capable of neutralizing phage. They subcultured plaques of phage particles which survived the neutralization experiment and showed that these were susceptible to antiphage serum neutralization and also exhibited similar anomalous neutralization behaviour. Delbrück (1945) observed a similar phenomenon with the $T 1$ coli phage and suggested that antibody might be attaching itself at sites on the phage where it would not interfere with infectivity. Hershey \& Bronfenbrenner (1952) believed that these anomalies might be due to an uncontrolled behaviour of complement. Thus, it is not clear whether the neutralization anomalies are a result of inherent heterogeneity of phage preparations or to the properties of specific lots of sera. 
It was of interest to consider the value of the present series of phages in defining the bacterial species of the genus Azotobacter. Considerable disagreement exists as to whether the group of organisms designated Asotobacter agilis (Bergey's Manual, 1957) comprise one or two species, namely $A$. agilis and $A$. vinelandii. Some investigations have shown morphological, ecological and physiological differences between these two groups of organisms. The present studies indicate a difference between these strains since 11 out of $12 \mathrm{~A}$. vinelandii strains showed lysis by one or more of the phages, whereas none of the six strains of $A$. agilis tested were lysed by any of the phages. Also, the strains designated $A$. macrocytogenes and $A$. insigne, which in many respects are similar to $A$. agilis cultures, were not lysed by any of the present phages. Since the $A$. agilis cultures have a distinct aquatic distribution and have never been isolated with certainty from the soil, it is possible that phages for these strains do not exist, or are rarely present, in the soil. Also, in the described phage isolation procedures the indicator strain used was a culture of $A$. vinelandii, a strain usually isolated from the soil. An exhaustive search for phages which lyse $A$. agilis strains using this culture as an indicator strain has not been made. The azotobacter phages described here are not species-specific since 14 out of 25 strains of $\boldsymbol{A}$. chroococcum tested were lysed by one or more of the phages. Jones (1959) showed that at least one strain of $A$. chroococcum may be lysogenic. Although a considerable amount of discussion regarding taxonomy of the genus Azotobacter has centred around the relationship of $A$. agilis and $A$. vinelandii, two classification proposals (Tchan, 1958; Jensen, 1955) were concerned with the relationship of $A$. chroococcum and $A$. vinelandii. On the basis that these two species possessed a dormant stage (microcysts) they were included in the genus Azotobacter separate from $A$. agilis, which was placed in the genus Azotococcus. The present studies indicate a similar strain relationship, since the phages lysed $A$. vinelandii and $A$. chroococcum, but did not lyse strains of $A$. agilis.

We wish to express our appreciation to Mr Maxwell Nimeck for technical assistance and to Mr Phillip Hodson for taking photographs of the phage plaques. This work forms part of a thesis presented (by J.T.D.) for the Ph.D. degree to the University of Texas.

\section{REFERENCES}

ADAMs, M. H. (1950). Methods of study of bacterial viruses. In Methods in Medical Research (ed. J. M. Comroe), vol. 2. Chicago: Year Book Publishers.

Adams, M. H. (1959). Bacteriophages. New York: Interscience Publishers Inc.

Adams, M. H. \& Park, B. H. (1956). An enzyme produced by a phage host cell system. II. The properties of the polysaccharide depolymerase. Virology, 2, 719.

ANDREWs, C. H. \& Elford, W. J. (1933). Observations on antiphage sera. I. The 'percentage law'. Brit. J. exp. Path. 14, 367.

Bergey's Manual of Determinative Bacteriology (1957), 7th ed. Ed. R. S. Breed, E. G. D. Murray and N. R. Smith. Baltimore: Williams and Wilkins Co.

Denbrück, M. (1945). Effects of specific antisera on the growth of bacterial viruses (bacteriophages). J. Bact. 50, 137.

Hershey, A. D. \& Bronfranbrenner, J. (1952). Bacterial viruses: Bacteriophages. In Viral and Rickettsial Infections of Man, 2nd ed. p. 190 (ed. T. M. Rivers). Philadelphia: Lippincott.

JENSEN, V. (1955). The azotobacter-flora of some Danish watercourses. Saetr. AF Bot. Tidsskr. 52, 143. 



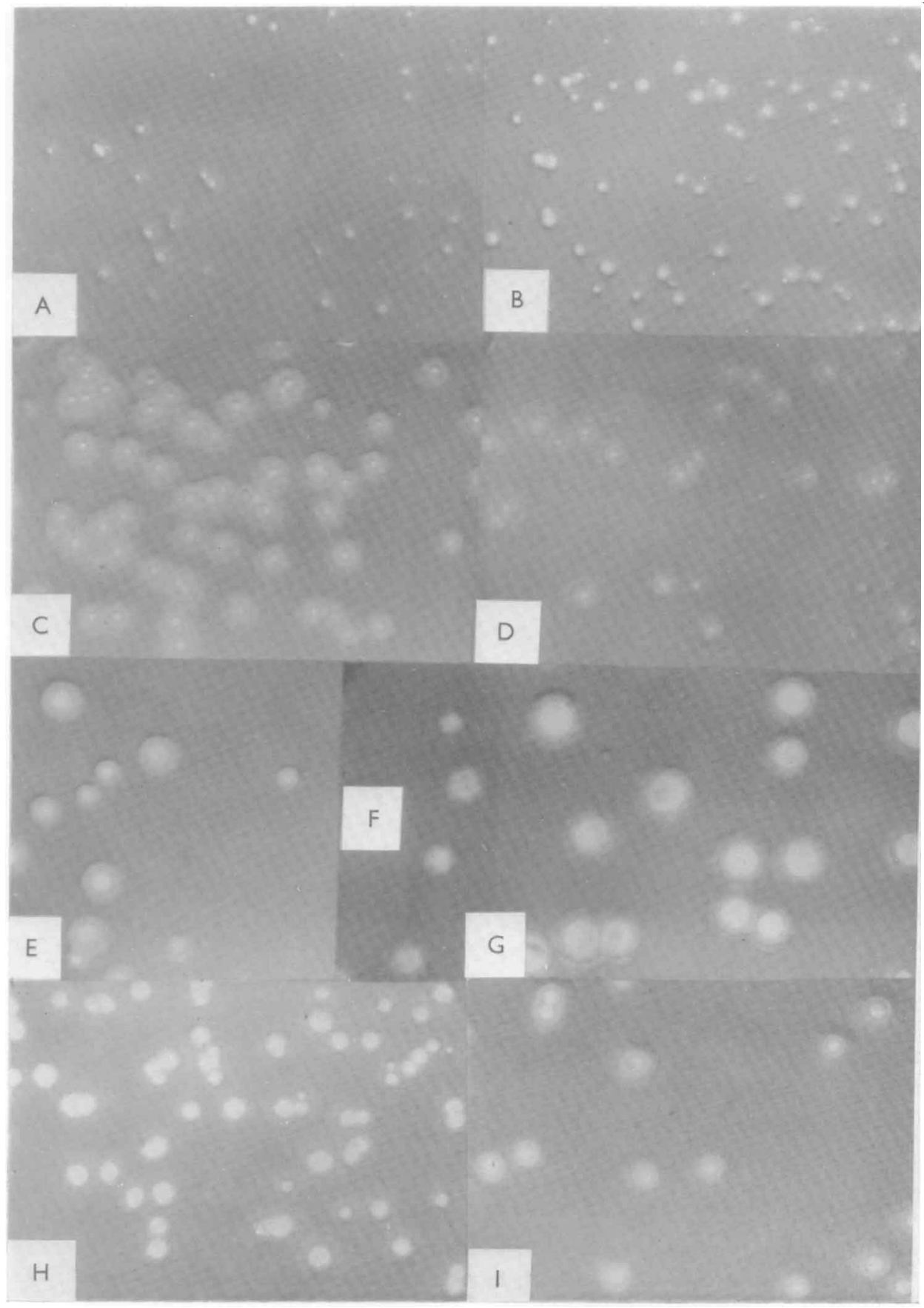

J. T. DUFF AND O. WYSS

(Facing p. 289) 
Jones, L. (1959). Lysogeny in azotobacter. Master's Degree Thesis, The University of Texas, Austin, Texas, U.S.A.

Kruloge, D. (1957). Azotobacter bacteriophage. Ph.D. Dissertation, The University of Texas, Austin, Texas, U.S.A.

Mossour, V. (1954). Some mutations within the genus Azotobacter. Ph.D. Dissertation, The University of Texas, Austin, Texas, U.S.A.

Monsour, V., WYss; O. \& KrLLoge, D. S. (1955). A bacteriophage for azotobacter. J. Bact. 70, 486.

Park, H. (1956). An enzyme produced by a phage host cell system: I. The properties of a Klebsiella phage. Virology, 2, 711 .

TCHAN, Y. T. (1953). Studies of nitrogen fixing bacteria. IV. Taxonomy of genus Azotobacter. Proc. Linn. Soc. N.S.W. 78, 85.

\section{EXPLANATION OF PLATE}

Representative plaque types of azotobacter phages on host strain Azotobacter vinelandii 0 . Fig. A, phage A-12; fig. B, phage A-14; fig. C, phage A-13; fig. D, phage A-11; fig. E, phage A-22; fig. $F$, phage A-21; fig. G, phage A-23; fig. H, phage A-41; fig. I, phage A-81. Magnification c. $\times 1.5$. 